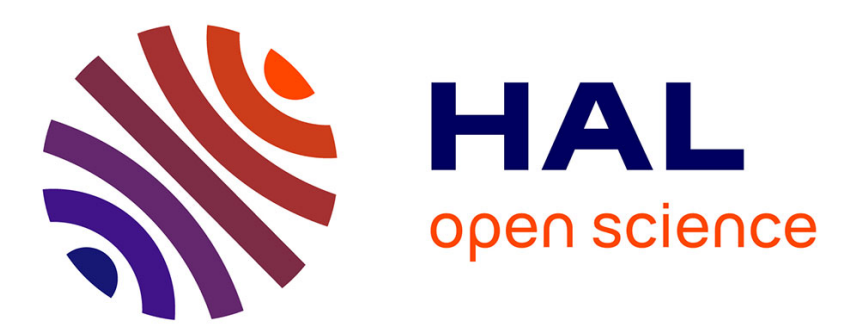

\title{
A new method to assess farming system evolution at the landscape scale
}

\author{
Pierre Chopin, Jean-Marc Blazy, Thierry Doré
}

\section{To cite this version:}

Pierre Chopin, Jean-Marc Blazy, Thierry Doré. A new method to assess farming system evolution at the landscape scale. Agronomy for Sustainable Development, 2015, 35 (1), pp.325-337. 10.1007/s13593-014-0250-5 . hal-01284267

\section{HAL Id: hal-01284267 \\ https://hal.science/hal-01284267}

Submitted on 7 Mar 2016

HAL is a multi-disciplinary open access archive for the deposit and dissemination of scientific research documents, whether they are published or not. The documents may come from teaching and research institutions in France or abroad, or from public or private research centers.
L'archive ouverte pluridisciplinaire HAL, est destinée au dépôt et à la diffusion de documents scientifiques de niveau recherche, publiés ou non, émanant des établissements d'enseignement et de recherche français ou étrangers, des laboratoires publics ou privés. 


\title{
A new method to assess farming system evolution at the landscape scale
}

\author{
Pierre Chopin • Jean-Marc Blazy • Thierry Doré
}

Accepted: 28 July 2014 / Published online: 28 August 2014

(C) INRA and Springer-Verlag France 2014

\begin{abstract}
Agriculture provides many ecosystem services such as food, fiber, clean water, and sequestration of carbon. The efficiency of such ecosystem services depends on crop composition and farmer decisions. Current knowledge on landscape changes is focused on crop allocation process at farm scale and rotations at field scale, whereas the impact of farmer decisions on the choice of crop acreages is poorly known. Therefore, we have built a method to assess the evolution of farm crop acreages in time and space and to identify factors ruling agricultural landscape changes. We use a dynamic typology, which is a multi-year classification of farmers. The seven steps of the method include three steps on farm typology, three steps on landscape changes, and then one step on change factors. We applied the method on 3,591 farms in Guadeloupe. Eight farm types were distinguished according to crop acreages. Our results show evidence of a diversification of 111 sugarcane growers toward production of vegetables and fruits. Spatial analysis revealed a relationship between diversification and water availability. Our method could be used to measure ecosystem services or disservices associated with changes in agricultural landscapes.
\end{abstract}

P. Chopin $(\bowtie) \cdot$ J.-M. Blazy

INRA, UR1321 ASTRO Agrosystèmes tropicaux,

F-97170 Petit-Bourg (Guadeloupe), France

e-mail: pichopin@gmail.com

J.-M. Blazy

e-mail: jean-marc.blazy@antilles.inra.fr

T. Doré

AgroParisTech, UMR 211 Agronomie,

F-78850 Thiverval-Grignon, France

e-mail: thierry.dore@agroparistech.fr

T. Doré

INRA, UMR 211 Agronomie, F-78850 Thiverval-Grignon, France
Keywords Agricultural landscapes · Farm typology · Cropping plan $\cdot$ Land-use dynamics $\cdot$ Regression tree . Spatial autocorrelation

\section{Introduction}

Agricultural landscapes account for one third of the human land use across the globe (FAOSTAT 2008). Agricultural practices have had a wide range of harmful effects on their surrounding environment, such as the degradation of soils, the loss of biodiversity, and the decrease of water quality, despite their ability to provide many fundamental ecosystem services to humanity (Tilman et al. 2002). The values and flows of these services are deeply linked to the crop composition and the crop arrangement in these landscapes (Castellazzi et al. 2010; Benoît et al. 2012; Schaller et al. 2012).

Both the composition and the configuration of agricultural landscapes are the result of farmer's cropping plan choices made at the farm level (Dury et al. 2011). A farm cropping plan is composed of (1) the crop acreages that refer to the farm area, usually devoted to one or a group of crops each year (Wijnands 1999) (Figs. 1 and 2) the crop allocation, which is the assignment of a particular crop to each plot on a given piece of land (Aubry et al. 1998). Crop rotation is defined as the practice of growing a sequence of plant species on the same land and is a concept that has long been used to represent the temporal dimension of cropping plan decisions (Bullock 1992). Different rules for crop rotation decisions affect farmer's crop acreages, such as the return period of crops, the maximum number of successive years that a crop may be grown in a field, and prohibited crop sequences (Castellazzi et al. 2007). A farmer's cropping plan and crop rotations are often spatially explicit at the farm scale (Rounsevell et al. 2003). They are determined by a range of factors that impact the farmer's decision process, including biophysical factors 


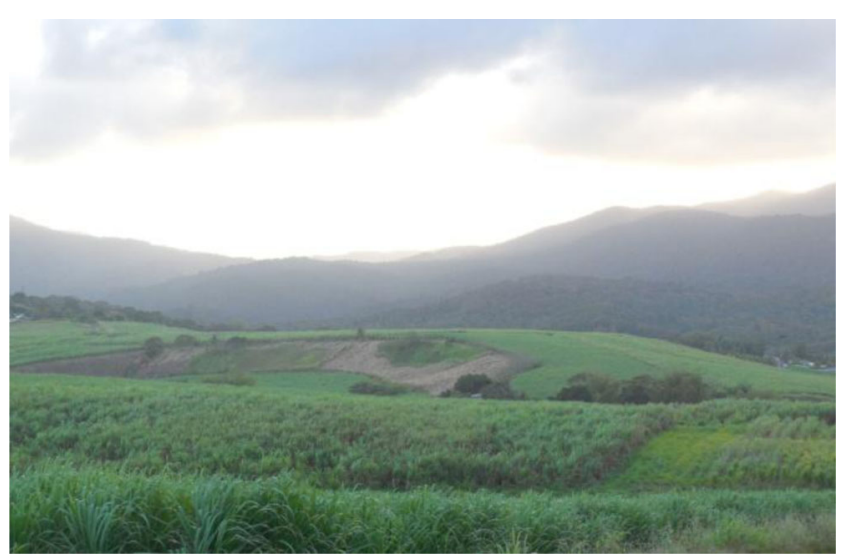

Fig. 1 Sugarcane and pasture are an important component of farmers' cropping plans in Guadeloupe, as shown in the agricultural landscape captured (e.g., slope and rainfall) and socioeconomic factors (e.g., farm size, and land tenure) (Leenhardt et al. 2010). At the regional scale, decision makers can strongly influence the provision of ecosystem services by modifying farmers' cropping plans according to agricultural policies that focus on these determining factors (Castellazzi et al. 2007; Valbuena et al. 2008).

The determinants of crop choices have been analyzed in a range of studies conducted within the "landscape agronomy discipline" (Benoît et al. 2012), which strongly focuses on the identification of patterns of crop rotations and the understanding of the process of crop allocations to plots. Patterns of crop sequences have been analyzed with special emphasis on the temporal and spatial evolution of the organization of crops (Benoit et al. 2001) and crop acreage changes at the regional scale (Mignolet et al. 2007) and very large scale (Xiao et al.

a Categorization of farms based on thresholds obtained with the regression tree $(n=3591)$

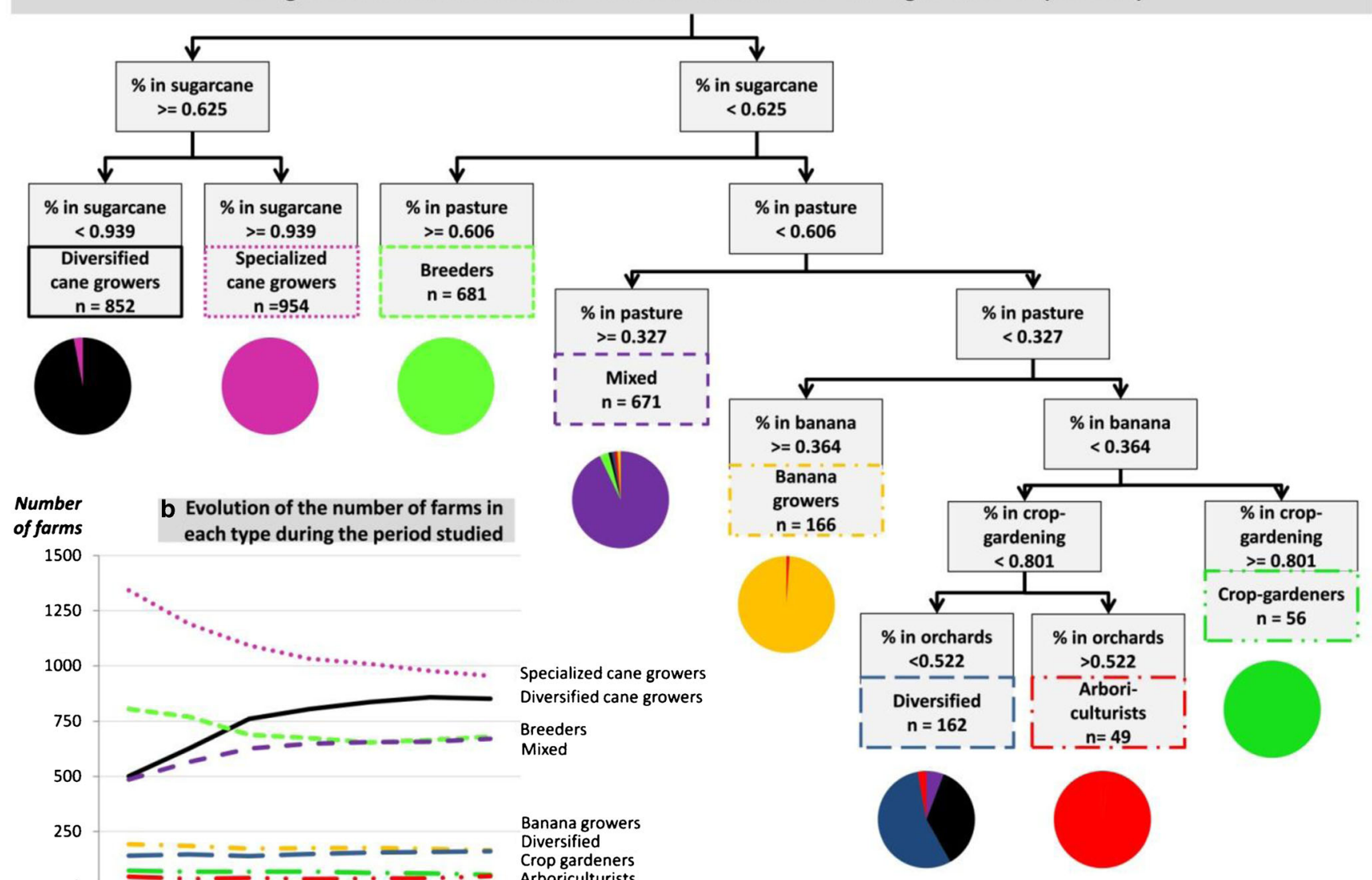

$20042005 \quad 2006 \quad 2007 \quad 2008 \quad 20092010$ Years

Fig. 2 a Shows the results of the regression tree for the population of farms. Thresholds for automatically categorizing farms are enclosed in light gray boxes, and the different farm types identified by the regression tree are given in colored boxes, with their numbers. The pie charts represent the proportion of each group from the ascending hierarchical classification included in each group obtained with the regression tree. We can see that the reproduction of groups from the cluster analysis is very good for seven of the eight groups. Only the classification of "diversified" farms is average, even though more than half of the group is constituted by farms classified as diversified in the hierarchical clustering analysis. In the pie chart of the diversified farm type, we can see that one third of this type is constituted by the "diversified cane growers" farm type, which is similar to the diversified farm type in its description because they both included diversified farms for which the proportion of sugarcane has decreased. b Shows the changes in the numbers of farm types from 2004 to 2010 in the selected population of farms ( $n=3,291$ farms). We can see that the number of "specialized cane growers" decreased from 1,300 to less than 1,000 while during the same period, the number of diversified cane growers increased rapidly 
2014). The landscape regularities caused by crop rotations, in time and space, have been analyzed by Schaller et al. (2012) who found that they were the results of decision rules for crop allocations made at the farm scale. Sorel et al. (2010) noted that this crop allocation process is influenced by the farm type, the field characteristics, and a range of agronomic factors. In these studies, the changes in cropping plan decisions were analyzed using an understanding of the changes in crop allocation processes as generally formalized with a set of rules (Aubry et al. 1998). In these studies, crop acreage choices are studied either at the regional scale, without consideration of the farmer's level of decision making, or at the farmer's level, without observing the aggregation of changes at the regional scale. This analysis at both farm and regional scale seems to be of a great importance for understanding the determinants of crop acreage changes at the regional scale and to help decision makers to formulate farm-scale policies intended to modify farming systems.

The most common approach to take account of crop acreages at the farm scale, when working at the regional scale, is farm typology, which categorizes farms into homogeneous groups with similar crop acreages. Comparisons of these groups are used to understand farmers' decision processes for crop choices (Iraizoz et al. 2007). Typologies are often built with either statistics, including principal component analysis and cluster analysis (which divide the overall farmer population into types), with expert knowledge, or with a mix of both approaches (Madry et al. 2013). Nonetheless, most farm typologies are static; they are made for a particular year and do not show changes over time and cannot, therefore, reveal the changes in farm cropping plans across time and space or the determinants of changes in farm cropping plans.

For analyzing the evolution of farm crop acreages over time and space, we propose a seven-step method that employs a dynamic farm typology, a multi-year classification of farmers into types: (1) to reveal the evolution of farm crop acreages across time and space and (2) to identify the determining factors of changes in agricultural landscapes. An understanding of such determinants can help decision makers to define agricultural policies that target the cropping plans of farmers to modify agricultural landscapes and, in turn, the provision of ecosystem services by these landscapes. The method is first presented with all its steps and then is applied to a case study of farms in Guadeloupe. Special attention will be paid to the provision of food for local markets, because the weak level of food self-sufficiency is one of the main problems for decision makers in Guadeloupe.

\section{Material and methods}

\subsection{Description of each step of the method}

The seven-step method includes the building of the farm typology in steps 1 to 3 and the assessment of changes in agricultural landscapes in steps 4 to 6 and highlights the determinants of changes in step 7 .

\subsubsection{Step 1: building the multi-annual farm database}

A geographical database of farms including data on their crop acreages, economic structure, and biophysical context is built for the study period, generally at least 5 years. Surveys of farm acreages and crop allocations to fields are generally available at the regional scale through public statistics and satellite imagery. However, information concerning the biophysical context and the structure of the farms can be scarce. Then, the databases need to be completed with relevant geographical information such as altitude, rainfall, and proximity to city. These data can be compiled from geographical information systems, census data, on-farm surveys, or field measures to provide a sufficient level of information about the hypothetical determinants of changes in farm cropping plans. The farms either can be mapped using the address provided in the database, by identifying farms with satellite imagery, or can be represented as the centroids of fields owned by farms.

\subsubsection{Step 2: building the farm typology}

The typology of farms is based on some variables describing the farm crop acreage for a given year of the study period, generally the first or the last year. Principal component analysis is first used to reduce the number of variables in the sample and to avoid problems associated with multi-collinearity. Then, relevant principal components are selected for the ascending hierarchical classification. After the ascending hierarchical classification, the partitioning of the population into homogeneous groups is performed using Ward's method (Ward 1963) to minimize the intra-group variability and maximize the inter-group variability (Blazy et al. 2009).

\subsubsection{Step 3: generating thresholds for the classification of farms}

Thresholds allow the allocation of a farm to a given type. This allocation for each year of the studied period allows the modeling of the dynamics of the typology. These thresholds are generated with a regression tree. Classification and regression tree (CART) techniques are statistical tools that have been used in agronomy mainly for identifying the factors controlling yield variability (Tittonell et al. 2010) or farming practices (Maton et al. 2007). In our study, the regression tree is used to classify farms into farm types during the study period. In the regression tree, the variable to be explained is the farm 
type obtained from the ascending hierarchical classification, and the explanatory variables are the crop acreages of the farms.

\subsubsection{Step 4: observing tendencies of farm type changes}

The categorization of each farm into a farm type for each year of the multi-annual database reveals the evolution of the number of farms of each type across the period studied. These evolutions show the tendencies of the number of farms of each type to increase or decrease.

\subsubsection{Step 5: generating farm transitions from type-to-type during the period}

Step 5 focuses on farm types, with significant increases or decreases to determine which types of farm transition are responsible for the significant temporal trends observed. Farm transitions are generated by examining the changes of various farm types during the study period. The transitions among farm types are summarized in a graph that combines all the significant transitions among types that occurred during the study period. This generation of farm transitions among all types allows for the identification of types responsible for the temporal trends observed in the previous step. For each transition, the farms belonging to the original types are mapped on the study area. These mapped farms include those that changed to another group during the studied period and those that stayed within the same type. Hence, the map identifies the areas where transitions have occurred and areas where the farm types have not changed.

\subsubsection{Step 6: detection of spatial autocorrelation in transitions}

The spatial influence on farm transitions is highlighted by performing spatial autocorrelation analyses on the map of farms. Spatial autocorrelation measures the degree to which a phenomenon is correlated to itself in space (Cliff and Ord 1973). It refers to either similar values statistically clustered in space or similar values dispersed all over the area of study. Absence of spatial autocorrelation indicates that the spatial pattern observed is random. One can thus identify two types of clusters: (1) positively autocorrelated areas in which the changes in the frequency of farm type are statistically greater than those of a random pattern of farms and (2) negatively autocorrelated areas in which the changes in farm type are statistically lower than the level of change of a random pattern of farms. A binary variable is created to identify the farms which have changed (binary variable 1) and those for which the type has not changed during the studied period (binary variable 0). Spatial autocorrelation is then performed on this binary variable. The farms for which the contribution to spatial autocorrelation, represented by the $\mathrm{Z}$-score, is above +1.96 or under -1.96 are selected because these values show a pattern of farm transition that is significantly different from a random pattern, at a confidence level of $95 \%$ (Ord and Getis 1995). These farms are then selected for regression analysis because they allow for a better identification of the determinants of changes in farm cropping plans.

\subsubsection{Step 7: identifying the drivers of changes in farm cropping plans}

To identify the determinants of changes in farm cropping plans, regression analysis is performed on the farms of the positively and negatively autocorrelated clusters in the studied area. The regression analysis quantifies the effects of the structural and biophysical variables of the farms on the importance of the local spatial autocorrelation, represented by the Z-score allocated to each farm. This method is similar to the one used by Chopin and Blazy (2013) to explain the origins of regional variability in crop yields by biophysical and socioeconomic determinants.

\subsection{Application of the method to Guadeloupian farms}

Guadeloupe is an archipelago located in the Caribbean. The 31,300 ha of the total farmed area is cultivated by 8,000 farmers all across the territory (Agreste 2011). Farm sizes range from less than 1 to more than 100 ha. The biophysical context of the farms varies from dry plains on calcic soils to andisols and nitosols located at high altitudes, where crops are grown on sloppy fields with high rainfall on very fertile clay soils. Rainfall in cultivated areas of Guadeloupe ranges from $800 \mathrm{~mm} \mathrm{yr}^{-1}$ in the dry plains to more than $4,000 \mathrm{~mm} \mathrm{yr}^{-1}$ at high altitudes. According to the regional statistics, sugarcane, pastures, and banana occupy, respectively, 14,000; 10,000; and 2,100 ha, and the other crops, less subsidized, including crop gardening, orchards, tubers, pineapple, and plantains occupy 3,000; 950; 350; 300; and 300 ha, respectively (Fig. 1). Guadeloupian agriculture is oriented toward the exportation of highly subsidized agricultural products, mainly bananas and sugar. Therefore, the food crop production does not meet the needs of the population, and consumers must buy expensive imported foodstuffs. The Guadeloupe regional council is willing to drive the local production toward an increase from the current level of food self-sufficiency. Our application will then focus on the types that can contribute to an increase in food self- 
sufficiency by the production of tubers, vegetables, and fruits.

\section{Results and discussion}

3.1 Results of the application of the method to the Guadeloupe case study

\subsubsection{A seven-year database comprising 3,591 farms}

We used a geographical database of individual fields, represented by polygons, corresponding to the annual declarations of farmers for obtaining subsidies. The annual databases, covering the period from 2004 to 2010, were merged together, and the 25,054 fields for which the crop type was declared for the entire period were selected. As shown in the two last columns of Table 1 , this multi-year database is quite representative of the regional statistics (Agreste 2011) as regards the areas of the subsidized crops of banana and sugarcane grown by more professional farmers, but less so for fruits and vegetables. We divided the numerous initial crops of our database into eight categories, "sugarcane," "banana," "pastures," "crop gardening," "tubers," "plantain," "pineapple," and "orchards," based on the similarity of the crop management system and the crop length cycle.

We generated the biophysical characteristics of field by using a geographical information system (GIS) and different layers of information in a shapefile or a raster format. Altitude information was obtained by using a $15-\mathrm{m}$ digital elevation model (DEM), a raster dataset representing the evolution of altitude over the region, which was produced with a map of altitude with contours every $5 \mathrm{~m}$, using the kriging tool from ArcGIS 9.3 (ESRI (Environmental Systems Research Institute) 2009). The rainfall layer used was obtained the same way with a shapefile of isohyets. The slope raster was obtained using the slope tool in ArcGIS 9.3 with the DEM as the input. Geostatistical analysis of fields with each generated raster provided the mean altitude, mean rainfall, and mean slope for each field of the database. The farm structure variables, represented by the farm size, the proportion of irrigable area, and the proportion of the farm in agricultural land management, were obtained either by a simple calculation or by a geographical treatment. The total cultivated area is the sum of the field areas of the farms. The proportion of irrigable area was based on a shapefile of irrigation schemes. The proportion of the farm area under each crop was obtained by dividing the area of each crop by the total cultivated area. This biophysical, agronomic, and farm structure information was upscaled from the field level to the farm level using the means weighted by the area of each field for each farm.

\subsubsection{A typology composed of eight types of farms}

The variables used in our typology are the proportions of the eight types of crops in the cultivated farm area (Table 1). The principal component analysis reduced the number of dimensions in our data according to the Kaiser's criteria to four principal components that had values above 1 . We used these four principal components in the ascending hierarchical classification and obtained eight groups (Table 1). This partition into eight groups is the one with the highest ratio of inter-group variability to intra-group variability. However, some degree of similarity exists between the "diversified" type and the "crop gardeners" type as well as between the "mixed cane growers-breeders" (called "mixed" in the rest of the paper) and the "diversified cane growers," as evident in the description of their mean crop acreages (Table 1).

The inter-group variability of the farm structure and the farm biophysical context in the overall population reflects the large diversity of farms in Guadeloupe. The descriptive statistics for the eight groups revealed a high level of specialization of five groups and a diversification for the three others (Table 1). The specialized producers, "cane growers," "breeders," "arboriculturists," crop gardeners, and "banana farms," respectively, specialized in sugarcane, beef production, perennial fruit production, crop gardening, and banana production for exportation. "Mixed" and diversified cane growers represent groups with two or three main products. For the first type, sugarcane and pasture are the only production types, while these crops are grown with a diverse group of crops in the second type. The diversified type includes farms that produce at least three or four crops, and pasture and sugarcane have the smallest acreages on the farm.

The groups crop gardeners, diversified, arboriculturists, and "banana growers" are localized on a high range of physical and structure context. On the opposite the groups, mixed, breeders, "specialized cane growers," and diversified cane growers are located in the same context (Table 1). Mixed producers, breeders, diversified cane growers and cane growers cultivate in average four hectares, the altitude of the farm is low (around 40 meters), the fields slope is weak, around $5 \%$ and rainfalls are in average around $2000 \mathrm{~mm}$ per year. Arboriculturists, crop gardeners, diversified and "banana growers" are located on a range of different biophysical contexts, and their intra-group structures strongly differ. The most import difference among these groups is the size of farms. "Banana grower" owns large farms around 15 ha in average, and the size of diversified farms is also above the average size of the farm population with 7 ha while crop gardeners and arboriculturists have the same mean size as the overall farm 


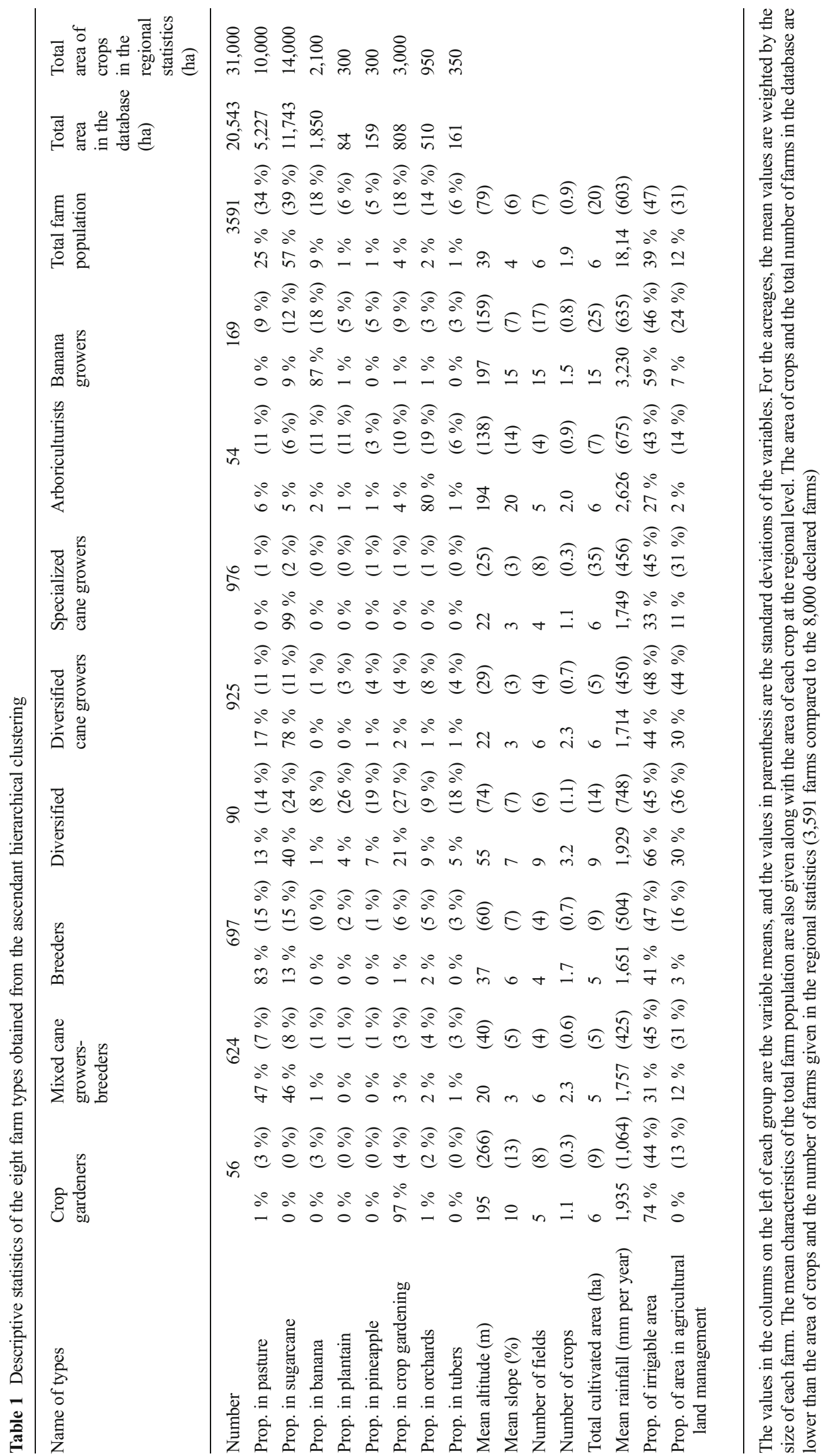


population. Diversified are located in average at lower altitudes than crop gardeners and arboriculturists, while banana growers are located on greater altitudes. Slopes also reflect the variability of biophysical contexts. They are quite high, between 10 and $20 \%$, but their standard deviation in these groups is really important $(15 \%)$. Crop gardeners are located in average on irrigation schemes while arboriculturists are outside of these schemes.

\subsubsection{Fourteen thresholds for crop acreages categorize farms into the eight farm types}

The regression tree generated 14 classification thresholds based on the proportions of crops within the farms' cropping plans. These thresholds enabled the automatic categorization of the farms of our geodatabase into one of the eight farm types for each year of the study period (Fig. 2). For each group obtained via the regression tree, the pie charts presented in Fig. 2 represent the proportion of the "initial" groups built from the ascending hierarchical classification. We can see from the pie charts that the regression tree produced similar results to the ascending hierarchical classification; for 7 out of the 8 farm types, more than $90 \%$ of farms were correctly classified. Only the diversified group was composed of a significant proportion of farms classified differently by the ascending hierarchical classification. In this group, $30 \%$ of the farms were classified as diversified cane growers by the ascending hierarchical classification. However, we consider the entire classification from the regression tree as valid because the two groups diversified and diversified cane growers are similar in terms of their descriptions. Furthermore, only $5 \%$ of the total number of farms in the population were categorized incorrectly. The 14 thresholds allowed for the automatic categorization of the population of 3,591 selected farms from 2004 to 2010.

\subsubsection{Farm type dynamics from 2004 to 2010}

We noticed a significant decrease in the number of specialized cane growers farm type between 2004 and 2010. In contrast, the number of diversified cane growers farms strongly increased (Fig. 2). Thus, the population of "specialized sugarcane growers" decreased from 1,400 in 2004 to less than 1,000 in 2010 , i.e., from $39 \%$ to $26 \%$ of the overall farm population. In contrast, the number of diversified cane growers farms increased from 500 to 800 , i.e., from $14 \%$ to $25 \%$ of the total farm population in 2010 .

\subsubsection{Summary of the transitions of farms among types}

All the farm changes from 2004 to 2010 have been summarized in terms of the number of changes over the period
(Fig. 3). A number of specialized cane growers transitioned to diversified cane growers. To test the ability of the method to explain transitions between farm types, we decided to focus on the determinants of the increase in the diversified cane growers farm type. This increase corresponds to the transitions of farms initially belonging to the breeders, specialized cane growers, and mixed farm types into diversified cane growers. These transitions reflect an important change in production from pasture and sugarcane to crop gardening and orchards. Indeed, crop gardening and orchards can be considered as more risky, more resource intensive (in terms of time, equipment and workforce), and also more profitable. The focus on these transitions revealed two different patterns among farm transitions. The first is a diversification process through the adoption of cattle breeding by farmers, while the second pattern is a diversification process associated with the adoption of vegetables or fruit production. We then decided to split the diversified cane grower type into two subgroups, a "diversified on animals" subgroup and a "diversified on fruits or vegetables" subgroup, according to the presence of fruits or vegetables in the farm acreage in 2010 , which was $10 \%$, on average, in 2010.

After splitting the diversified cane grower type into subgroups, we focused on the transitions from specialized cane growers, mixed, and breeders to "diversified on vegetables and fruits" in order to understand the process of crop acreage changes toward production of food for local consumers. An understanding of the determinants of farm cropping plan changes toward the diversification of crops is of a great importance to propose adapted agricultural policies aimed at increasing the level of food self-sufficiency in Guadeloupe. We then mapped the 2,504 farms belonging to the specialized cane growers, breeders, and mixed groups in 2004. Of these 2,504 farms, 111 farms changed to the "diversified on fruits or vegetables" type. This number represents a small proportion of the farms in Guadeloupe, but this transition can be used as a basis for understanding the determinants of the diversification process in Guadeloupe. A binary variable was used in the spatial autocorrelation analysis to identify the 111 farms that changed to the "diversified on vegetables and fruits" farm type.

\subsubsection{Groups of autocorrelated farms in transitions}

The sixth step is the spatial autocorrelation analysis of the population of farms to identify areas where (1) statistically, more transitions have occurred from one group to another and (2) areas in which farms have, statistically, less transitions (Fig. 4). The spatial autocorrelation analysis of farms based on the binary variable identified three areas, two areas of positive spatial autocorrelation and one area of negative spatial autocorrelation. We selected the 1,280 farms that were 


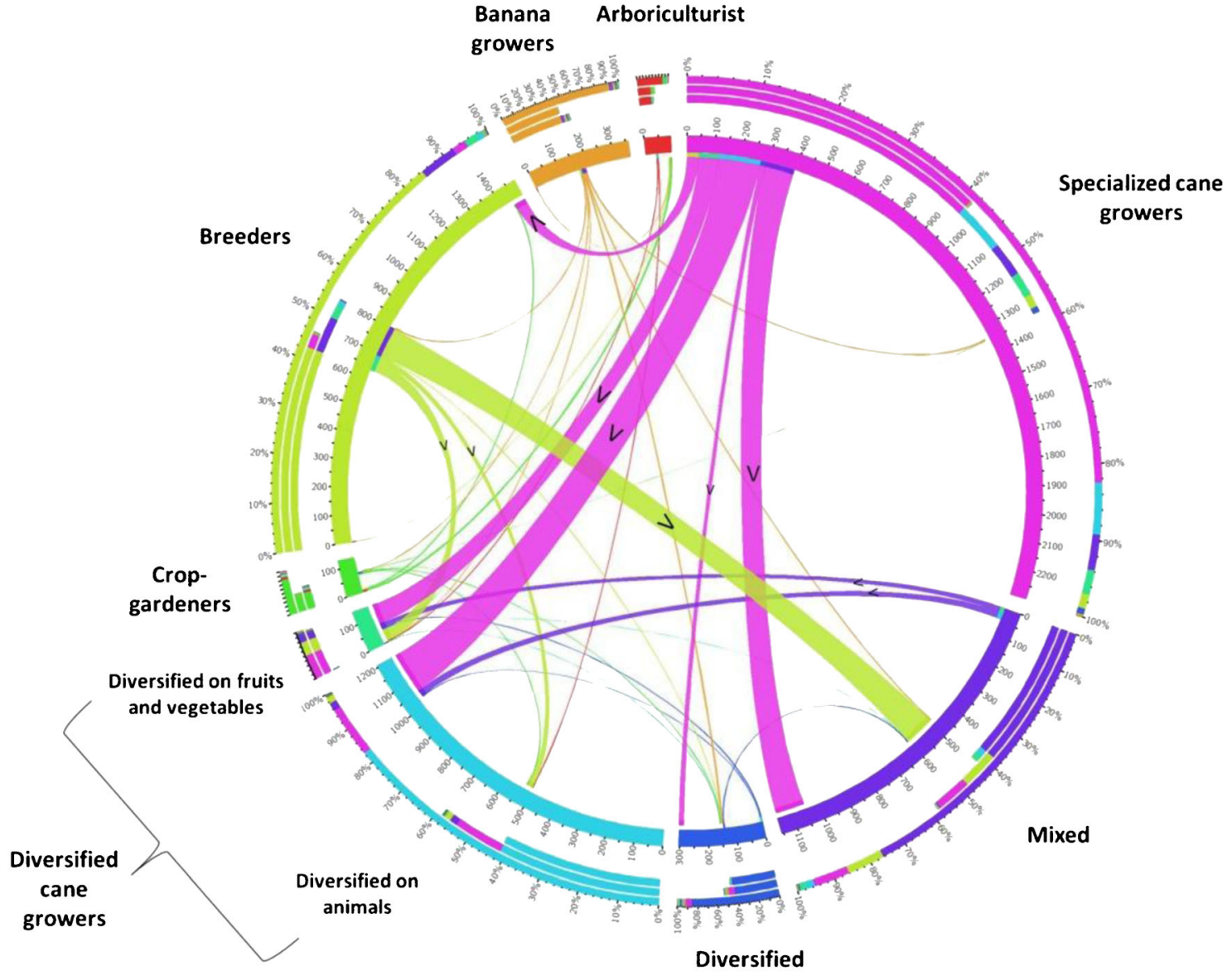

Fig. 3 Circular plot of farm types in 2004 and the representation of their transition during the period 2004 to 2010 for the selected population of farms ( $n=3,291$ farms). Ribbons between types represent the transition of farms from a given type in 2004 to another one in 2010. Ribbon width represents the number of farms in transition. Direction of transitions is represented by an arrow. The angular sizes of circularly arranged segments represent the population of each type (with their corresponding color used in Fig. 2) and are proportional to the size of farm types in 2004. The four circularly arranged stake bars, from the center of the figure to the edges, represent respectively, the relative contribution of outgoing

highly negatively and positively autocorrelated within these three clusters for regression analysis.

\subsubsection{Access to irrigation for crop growth explains} the observed changes in farm cropping plans

$$
\begin{aligned}
\text { Zscore } & =5.489+0.568(\text { slope })-0.004(\text { rainfalls }) \\
& +0.006(\text { cultivated area }) \\
& +0.833(\% \text { farm in irrigation scheme }) \\
& +0.198(\% \text { farm in land management }) \\
R^{2}= & 0.77 \text { and Mean rainfalls }(P<0.01)
\end{aligned}
$$

Prop. farm in irrigation scheme $(P<0.01)$ ribbons from each farm type in number of farms in percentage, the relative contribution of ingoing ribbons to each farm type in percentage, and the proportion of ingoing and outgoing ribbons in the total population. The "diversified cane growers" group was split into two subgroups, "the diversified on animals" and the "diversified on fruits and legumes" subgroups. The latter reflects the adoption of legumes and fruit crops by 111 farms from the "specialized cane growers," "mixed," and "breeders" farm types, represented by the flows to "diversified on fruits or legumes"

A multiple linear regression performed on the 1,280 selected farms in the three above-mentioned clusters revealed the influence of the access of farms to irrigation and the amount of rainfall on the diversification process (see the Eq. 1). The presence of farms within irrigation schemes was positively correlated to the transition of farms to "diversified on vegetables and fruits," while the amount of rainfall was negatively correlated to the diversification toward vegetables and fruits. This finding can be explained by the fact that vegetables and fruits need to be irrigated in dry areas because of the lack of water from rainfall, while the amount of water is too high in humid areas where rainfalls are close to $3,000 \mathrm{~mm}$. This high amount of water can cause waterlogging and drive the development of pests and diseases that strongly decrease the yields of vegetables and fruits (while pasture and sugarcane are resistant to this phenomenon). 


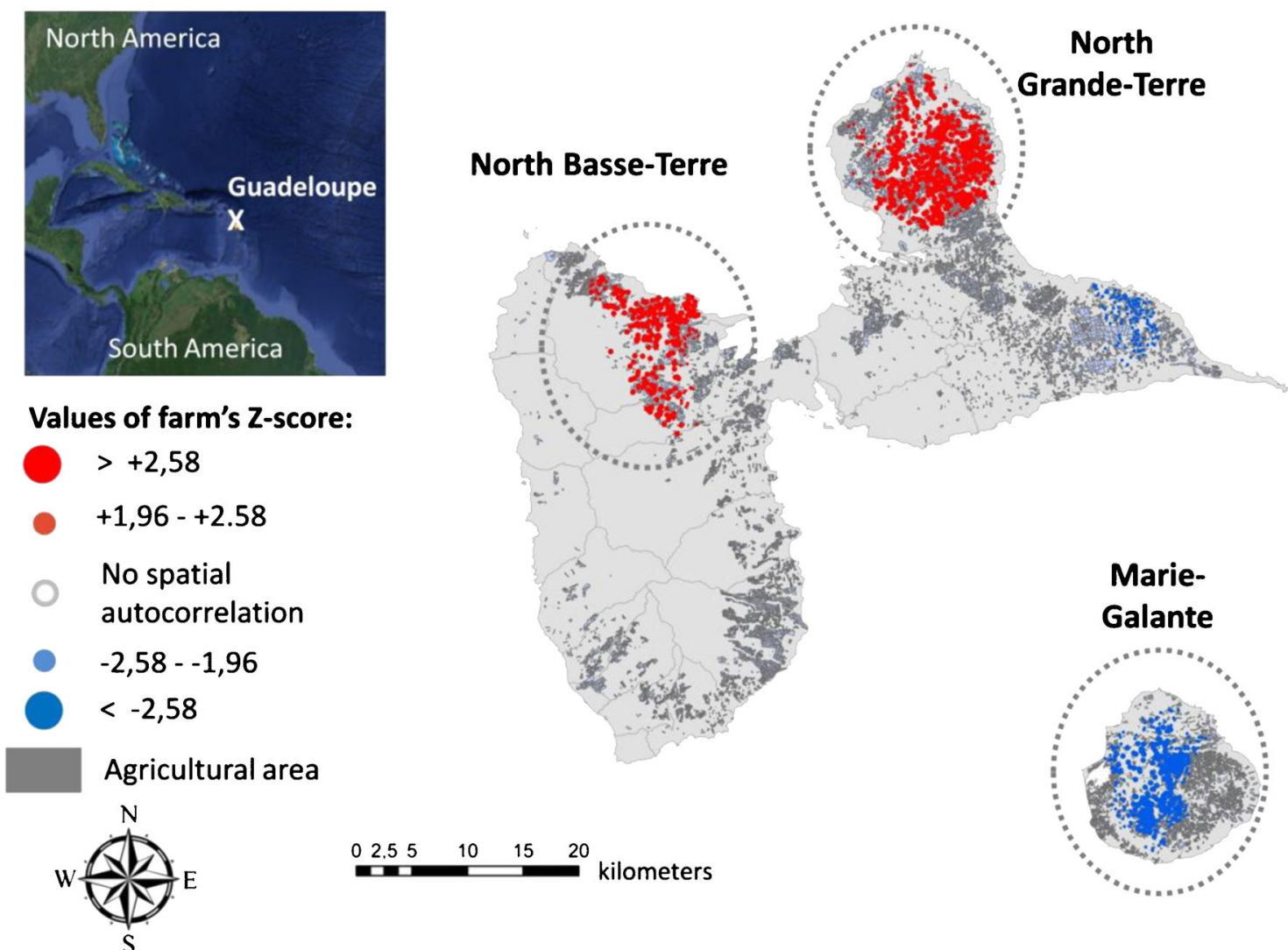

Fig. 4 Map of the level of local spatial autocorrelation, highlighting the areas where farms from the "breeders," "specialized cane growers," and "mixed" groups changed to "diversified cane growers in legumes and fruits." The hot spots shown in red are farms in areas where the changes in farm type are statistically greater than those of a random pattern of farms,

3.2 Discussion of the method for understanding the determinants of change in farm cropping plans

\subsubsection{Automatic classification of farms into farm types facilitates monitoring of the impacts of agricultural policies on farms}

The construction of thresholds for categorizing the farms into farm types can facilitate the identification of tendencies for decreases or increases in the number of farms of various types over a territory. This automatic classification is particularly useful for decision makers to follow the dynamics of change at the scale of the farm in addition to the regional scale. This automatic categorization is fast because it does not require repeating a statistical analysis on databases for every survey. This automatic classification also does not require the intervention of expert knowledge for classifying farms into groups. Thus, this method is particularly useful in the context of the high frequency of farmer interviews and census that encompass a wide range of information about a farmer's activities on while cold spots shown in blue are areas where the changes in farm type are statistically lower than in a random pattern. Three areas are significantly different; the "North Grande-Terre" and the "North Basse-Terre" areas have a high number of changes in farm type, while the number of changes is low in the "Marie-Galante" area

their farm. Using the method for several years can help local agricultural policy makers to easily follow the evolution of farmers' cropping plans and assess the effectiveness of agricultural policies aimed at changing the agricultural landscape.

Regression trees are characterized by rough discontinuity, which means that small changes in a farmer's cropping plan can generate a change in farm type. In our study, this threshold effect could be important for farms cultivating few fields. The change of a crop in one or two fields can create a significant change in crop acreages at the farm scale and thus a change in farm type. These changes in farm type could occur several times for a given farm as a result of crop rotations for instance. It is difficult to know if farm type changes are caused by crop rotation effects or a long-lasting change in the activities of the farm. In our case study, this problem is minimized by the high number of farms included and by the fact that sugarcane- and pasture-based farm types, e.g., breeders, mixed, and specialized cane growers, do not perform crop rotations; therefore, their inter-annual variations in crop acreage at 
the farm scale are minimized. This problem can also be minimized by characterizing the pattern of crop rotations at a regional scale that are common to different farms (Benoît et al. 2001; Mignolet et al. 2007). Instead of building a typology on crop acreages, it can be built on proportions of different crop rotations at the farm scale. Considering crop rotations directly can prevent us from over-estimating the farm type changes based on crop acreages at the farm scale. A new crop rotation in the cropping plan of a farm can then be considered as a change in farm type toward another form of crop production.

\subsubsection{Transitions of farms among farm types}

The main advantages of our method rely on its ability to assess the evolution of agricultural landscapes at the farm scale through the analysis of the changes in the number of farm types over time. Our method insures invariability in the description of types, which reveals that the farm cropping plan changes by the changes in farm types. In previous studies (Iraizoz et al. 2007; Mignolet et al. 2007), farm typologies were static, and several statistical treatments were required to generate a dynamic typology. However, these multiple treatments modified the description of groups across the period studied. The study of determinants with these treatments may have introduced bias into the analysis of determinants because a farm with the same crop acreages can be categorized into different types across the study period because of the changes in the definitions of the farm types.

In our method, we can identify the farms within farm types responsible for the temporal tendencies observed. The transitions of farms from one type to another are all described for the period studied. The explicit changes in the farm types of all the farms in our case study allow for the identification of the transitions among groups. These transitions are an indicator of farm cropping plan changes across the territory. Iraizoz et al. (2007) realized a typology for studying the trajectories of changes in farm structure over time. The dynamic dimension of their typology was the measure of the annual percentage change of the structure variable for 4 years, but no change of the structure over time was presented. The indicator of changes in farm cropping plans available with our typology allows for the better identification of the spatial factors that determine the changes in farm cropping plans.

The method needs to be applied to a multi-year database in order to observe trends among farm types. The time scale of the multi-year database should be based on the availability of data for the study area and on the duration of crops in the area. In our study, the main crops, bananas and sugarcane, are grown for 7 years on average before being destroyed. Hence, the use of a 7-year database seemed appropriate to see changes taking place in farmers' crop acreages.

\subsubsection{Identifying the determinants of changes for spatially targeted agricultural policies}

Transitions are defined not only by an increase or a decrease in the number of farm types but also by the location of the temporal transitions observed with the method. Focusing on the farms from positively and negatively autocorrelated clusters helps by statistically highlighting the determinants of farm changes. The residuals of the model we built to explain the transition of farms toward the subgroup "diversified on fruits or vegetables" were tested for spatial autocorrelation to reveal any bias in the estimation of parameters of farm type changes, as in Chopin and Blazy (2013). The spatial autocorrelation tests did not reveal any autocorrelated pattern of farm changes in the residuals of the regression model. This verification ensured us that the estimations of the parameters in the regression analysis were not biased.

This method enables the identification of the determinants of changes in farm cropping plans and, in turn, the changes in agricultural landscapes. In our case study, the determining effect of the access to irrigation can drive agricultural policies toward the provision of a sufficient amount of water to farms located in dry areas to reach the regional objective for food self-sufficiency. Providing access to irrigation to the farmers is a lever of action to promote conversion from sugarcane- and pasture-based systems to fruits or vegetables. This process of diversification of cane-based farms can then be increased by an extension of the irrigation schemes in dry areas where canebased farms are located, as has been done in the north GrandeTerre area since the beginning of the 2000's (Cabidoche et al. 2002). In the West-Grande Terre area, the trend toward diversification is weak since this diversification process took place in the 1980s with the opening of irrigation schemes. In contrast, the results of the analysis demonstrated that high levels of rainfall were a constraint to the adoption of crop gardening production in humid areas. This is particularly true in the South Basse-Terre area, where the decrease in the banana area has not been accompanied by a significant increase in market gardening. This is due to the presence of polluted soils that prohibit the cultivation of roots and some vegetables (e.g., zucchini; see Cabidoche et al. 2009) and the lack of rainfall in the dry season that cannot be corrected by irrigation due to the absence of irrigation schemes. Considering the high cost of drainage of water from a field, innovative crop gardeningbased cropping systems can be designed to respond to this important constraint. Thus, crop rotations should be designed with an emphasis on the resistance of crops to waterlogging effects and high pest infestations when the rainfall levels are important. These systems can be prototyped for all the pedoclimatic areas of Guadeloupe by taking into account the biophysical and the socioeconomic contexts of the farms and the objectives of farmers in these areas. This prototyping method can be based on the modeling of the adoption of 
innovative cropping systems by farmers, contributing to an increase in food self-sufficiency in Guadeloupe (Blazy et al. 2009).

Other geographical factors can explain the absence of changes in farm types toward diversification. For instance, the level of subsidies can explain the absence of transitions of banana farms toward more diversified farm types during the study period. The economic context of banana production, which is affected by the common market organization (CMO) that will lead to the end of banana quotas and taxes, will most likely threaten banana production and exportation in Guadeloupe by 2020 because of its low degree of competitiveness in the world market. Thus, other possible determinants of changes in farm cropping plans to other farm types should be investigated to identify all the levers of action toward the diversification of crops for each type of farm. The lack of data on the structure of farms and the personal objectives of farmers in the database we used makes it difficult to determine all of the determinants of changes in crop acreages at the farm scale. Complementing our study with on-farm surveys would help gather new information and data concerning the process of diversification. As proposed by Debolini et al. (2013), mapping the knowledge of agricultural experts would be a good step to perform before surveying farmers. These experts would most likely be able to provide a range of possible constraints to the diversification of farm types.

As we showed in Table 1, this multi-year database is less representative of the regional statistics for fruit and vegetables than for sugarcane and pasture. The number of farms geared to the production of fruit and vegetables is thus probably underestimated in our study. This lack of farms was identified in all the districts of Guadeloupe in a homogeneous way based on 2010 census data. The access to irrigation is a determinant of change from cane- and pasture-based types to "cane growers diversified on fruit and vegetables" that can be equated to the missing farms in our database. This lack of farms in our data appears as a constraint for the application of our method since it reduces the probability of identifying a trend in the number of farm types.

This method can help to assess ecosystem services provided by agriculture at the regional scale. This supply of ecosystem services is the contribution of agriculture to sustainable development. For instance, in our example, the development of fruit and vegetables in "cane growers diversified on fruit and vegetables" can enhance the provision of food, but at the same time, the use of irrigation in new areas can decrease the regulatory service of agriculture for the purification of water, with an increase in pollution due to intensive farming practices. Such ecosystem services can be appraised using indicators to measure their provision at the regional scale. These indicators use information about cropping systems, e.g., the yield or the use of pesticides, and upscale this information from field to region in order to measure these services. An assessment of different types of services from year to year can help characterize the trade-offs between the production of food and the provision of clean water by agriculture.

\section{Conclusion}

The method developed here differs from the methods currently used for examining changes in farm cropping plans because it is mainly based on the analysis of farm crop acreages in contrast to other methods that focus on the crop allocation process. The typology developed with our method ensures a dynamic and automatic representation of the evolution of farm types over several years, based on crop acreage choices. This dynamic reveals the temporal and spatial tendencies of changes in farm cropping plans during the studied period as well as the transitions among groups. This temporal and spatial characterization aids in the identification of the determinants of the changes in farm cropping plans. This method also avoids bias in the analysis of the influence of determinants by assessing spatial autocorrelation and providing a description of the farm types that remain the same over time. Furthermore, this rapid classification method is particularly useful for following the evolution of the farm population and assessing the effectiveness of agricultural policies on the changes in cropping plans that are reflected in the changes in the number of farms of each type. Using the method to examine a larger database, with more structure data and socioeconomic information, would increase the number of geographical factors to be tested as possible determinants of change. The analysis would then help decision makers to drive the changes in farm cropping plans toward a desired state, such as an increased level of food self-sufficiency in Guadeloupe, by using determinants as possible levers of action.

Our method could be used as a prerequisite for assessing the trade-offs in the provision of ecosystem services associated with land use changes. The provision of ecosystem services is a multi-criteria problem, and a change in farm cropping plans can provoke multiple effects on different ecosystem services. In our method, each farm type is described by the mean farm crop acreages. For each acreage, at each different location, we can derive a mean level of the provision of ecosystem services. Then, by analyzing the influence of determinants on the changes in farm cropping plans, we would be able to characterize the changes in agricultural landscape and the provision of ecosystem services. In order to measure the provision of 
ecosystem services and determine the trade-offs among these services, indicators can be designed. These indicators use the information on cropping practice at the field scale and upscale this information to the regional scale in order to determine these trade-offs. Finally, the method can allow for the measurement of the overall contribution of the agricultural landscape to the sustainability of a territory.

Acknowledgments The authors wish to thank the Agrigua Association, the National Institute of Geographic and Forest Information (IGN), the Guadeloupe department of public works, land use and housing (DEAL), and the Guadeloupe Chambers of Agriculture (CA) for providing the geographical information used in this study. The first author benefited from a $\mathrm{PhD}$ grant co-financed by the European Union (Fonds Social Européen), Guadeloupe Regional Council, and INRA EA department. We would like to thank the two anonymous reviewers for their helpful comments on the first version of the manuscript. Authors would like to deeply thank Dr Yves-Marie Cabidoche, who passed away in June 2012, and to dedicate this article to him.

\section{References}

Agreste (2011) Guadeloupe-Mémento Régionale-Résultats 2011. http:// www.agreste.agriculture.gouv.fr/IMG/pdf/D97113C01.pdf. Accessed 26 March 2014

Aubry C, Papy F, Capillon A (1998) Modelling decision-making processes for annual crop management. Agric Syst 56(1):45-65. doi:10. 1016/s0308-521x(97)00034-6

Benoît M, Le Ber F, Mari J-F (2001) Recherche des successions de cultures et de leurs évolutions: analyse par HMM des données TerUti en Lorraine. La Stat Agric 31:23-30

Benoît M, Rizzo D, Marraccini E, Moonen A, Galli M, Lardon S, Rapey H, Thenail C, Bonari E (2012) Landscape agronomy: a new field for addressing agricultural landscape dynamics. Landsc Ecol 27(10): 1385-1394. doi:10.1007/s10980-012-9802-8

Blazy J-M, Ozier-Lafontaine H, Dore T, Thomas A, Wery J (2009) A methodological framework that accounts for farm diversity in the prototyping of crop management systems. Application to bananabased systems in Guadeloupe. Agric Syst 101(1-2):30-41. doi:10. 1016/j.agsy.2009.02.004

Bullock DG (1992) Crop-rotation. Crit Rev Plant Sci 11(4):309-326. doi: 10.1080/07352689209382349

Cabidoche Y-M, Cattan P, Dorel M, Paillat J-M (2002) Intensification agricole et risque de pollution azotée des ressources en eau dans les départements français d'outre-mer insulaires: surveiller en priorité les pratiques agricoles dans les périmètres irrigués. Atelier du PCSI (Programme Commun Systèmes Irrigués) sur une Maîtrise des Impacts Environnementaux de l'Irrigation. hal. inria.fr/docs/00/18/07/27/PDF/Cabidoche.pdf. Accessed 26 March 2004

Cabidoche YM, Achard R, Cattan P, Clermont-Dauphin C, Massat F, Sansoulet J (2009) Long-term pollution by chlordecone of tropical volcanic soils in the French West Indies: a simple leaching model accounts for current residue. Environ Pollut 157:1697-1705. doi:10.1016/j.envpol.2008.12.015

Castellazzi MS, Perry JN, Colbach N, Monod H, Adamczyk K, Viaud V, Conrad KF (2007) New measures and tests of temporal and spatial pattern of crops in agricultural landscapes. Agric Ecosyst Environ 118(1-4):339-349. doi:10.1016/j.agee.2006.06.003
Castellazzi MS, Matthews J, Angevin F, Sausse C, Wood GA, Burgess PJ, Brown I, Conrad KF, Perry JN (2010) Simulation scenarios of spatio-temporal arrangement of crops at the landscape scale. Environ Model Softw 25(12):1881-1889. doi:10.1016/j.envsoft. 2010.04.006

Chopin P, Blazy J-M (2013) Assessment of regional variability in crop yields with spatial autocorrelation: Banana farms and policy implications in Martinique. Agric Ecosyst Environ 181(0):12-21. doi:10. 1016/j.agee.2013.09.001

Cliff AD, Ord JK (1973) Spatial autocorrelation. Monographs in spatial and environmental systems analysis. Pion, London

Debolini M, Marraccini E, Rizzo D, Galli M, Bonari E (2013) Mapping local spatial knowledge in the assessment of agricultural systems: A case study on the provision of agricultural services. Appl Geogr 42(0):23-33. doi:10.1016/j.apgeog. 2013.04.006

Dury J, Schaller N, Garcia F, Reynaud A, Bergez J-E (2011) Models to support cropping plan and crop rotation decisions. A review. Agron Sustain Dev 32(2):567-580. doi:10.1007/s13593-011-0037-x

ESRI (Environmental Systems Research Institute) (2009) ArcGIS 9.3.1. Environmental Systems Research Institute, Redlands, California, USA

FAOSTAT (2008) FAO Statistics Database Rome, Italy

Iraizoz B, Gorton M, Davidova S (2007) Segmenting farms for analysing agricultural trajectories: A case study of the Navarra region in Spain. Agric Syst 93(1-3):143-169. doi:10.1016/j.agsy.2006.05.002

Leenhardt D, Angevin F, Biarnes A, Colbach N, Mignolet C (2010) Describing and locating cropping systems on a regional scale. A review. Agron Sustain Dev 30(1):131-138. doi:10.1051/agro/ 2009002

Madry W, Mena Y, Roszkowska-Madra B, Gozdowski D, Hryniewski R, Castel JM (2013) An overview of farming system typology methodologies and its use in the study of pasture-based farming system: a review. Span J Agric Res 11(2):316-326. doi:10.5424/sjar/ 2013112-3295

Maton L, Leenhardt D, Bergez JE (2007) Geo-referenced indicators of maize sowing and cultivar choice for better water management. Agron Sustain Dev 27:377-386. doi:10.1051/agro:2007018

Mignolet C, Schott C, Benoit M (2007) Spatial dynamics of farming practices in the Seine basin: methods for agronomic approaches on a regional scale. Sci Total Environ 375(1-3):13-32. doi:10.1016/j. scitotenv.2006.12.004

Ord JK, Getis A (1995) Local spatial autocorrelation statistics: distributional issues and an application. Geogr Anal 27:286-306. doi:10. 1111/j.1538-4632.1995.tb00912.x

Rounsevell MDA, Annetts JE, Audsley E, Mayr T, Reginster I (2003) Modelling the spatial distribution of agricultural land use at the regional scale. Agric Ecosyst Environ 95(2-3):465-479. doi:10. 1016/s0167-8809(02)00217-7

Schaller N, Lazrak EG, Martin P, Mari JF, Aubry C, Benoit M (2012) Combining farmers' decision rules and landscape stochastic regularities for landscape modelling. Landsc Ecol 27(3):433-446. doi: 10.1007/s10980-011-9691-2

Sorel L, Viaud V, Durand P, Walter C (2010) Modeling spatio-temporal crop allocation patterns by a stochastic decision tree method, considering agronomic driving factors. Agric Syst 103(9):647-655. doi: 10.1016/j.agsy.2010.08.003

Tilman D, Cassman KG, Matson PA, Naylor R, Polasky S (2002) Agricultural sustainability and intensive production practices. Nature 418(6898):671-677. doi:10.1038/nature01014

Tittonell P, Muriuki A, Shepherd KD, Mugendi D, Kaizzi KC, Okeyo J, Verchot L, Coe R, Vanlauwe B (2010) The diversity of rural livelihoods and their influence on soil fertility in agricultural systems of East Africa - a typology of smallholder farms. Agric Syst 103(2): 83-97. doi:10.1016/j.agsy.2009.10.001

Valbuena D, Verburg PH, Bregt AK (2008) A method to define a typology for agent-based analysis in regional land-use research. 
Agric Ecosyst Environ 128(1-2):27-36. doi:10.1016/j.agee.2008. 04.015

Ward JH (1963) Hierarchical grouping to optimize an objective function. J Am Stat Assoc 58:236-244

Wijnands E (1999) Crop rotation in organic farming: theory and practice. In: Olesen JE, Eltun R, Gooding MJ et al (eds)
Designing and testing crop rotations for organic farming. DARCOF, Foulum, pp 21-36

Xiao Y, Mignolet C, Mari J-F, Benoit M (2014) Modeling the spatial distribution of crop sequences at a large regional scale using landcover survey data: a case from France. Comput Electron Agric 102(0):51-63. doi:10.1016/j.compag.2014.01.010 